\title{
Contemporary Pattern Analysis of Mental Health Education in Colleges under the Professional and Social Responsibility Perspective
}

\author{
Yumei Jing \\ Hubei Normal University, HuBei HuangShi, 435000, China
}

\begin{abstract}
In this paper, we conduct contemporary pattern analysis of mental health education in the colleges under the professional and social responsibility perspective. About the definition of mental health, most people tend to a positive and continuous development of psychological situation as the individual under this kind of condition has a good adaptability can give full play to the potential of body and mind, and is much more than the absence of mental illness. For the college students, we should consider the career and social factors as the additional components. Colleges and universities should insist on school mental health education personnel training, obey the demands of the school student management follow the basic principles of the campus stability. Our research proposes the new perspective on the corresponding issues that will be meaningful and necessary.
\end{abstract}

Keywords: Pattern Analysis; Mental Health Education; Social Responsibility; Perspective.

\section{Introduction}

It is unceasingly thorough along with our country market economy system reform and the rapid development of higher education, college students' psychological presents new characteristics, main performance for the social experience, psychological not mature, the self-image high and the volatile mood, etc. This makes the current college students' psychological problems is complicated, and the overall poor psychological quality. Therefore, how to build college mental health education mode becomes an important subject in front of us.

Theory of synergetic also called synergy or union is the study of the system under the effect of the mutual coordination between each subsystem, the science of system from disorderly to the orderly transition. Most of the current psychology education patterns are built up based on this foundation that can be separated into the listed aspects. (1) Synergy "reveals the mechanism and law of system from disorderly to orderly, advanced the theory of self-organization. The so-called self-organization is system under the certain condition of the outside world (parameter), when it reaches a critical value, relationship between neutron systems can overcome the independence movement and spontaneous collaboration phenomenon. (2) "Synergy in order", orderly is the product of synergy. The critical conditions of forming cooperative movement, it argues, system is the organic connection between each subsystem in the system, collaboration and that cooperation. Among the factors such as system, independent of each other, each other, it shouldn't be making any ordered structures. (3) The function of the system structure of decision system, the different structure can produce different functions. In addition, in a complex system composed of synergy and other subsystems, the overall function of the system is not only the sum of the function of each subsystem, also includes the subsystems linked to form ordered structure and function.

Responsibility for education is to cultivate educates sense of responsibility, sense of mission of education. This responsibility includes to himself and to the others, to family and society, of human responsibility, etc. In today's highly developed society, education is an eternal topic that is the core revitalization of the nation, the only way for countries. College their social responsibilities and people often study of inclusion and exclusion of corporate social responsibility is different. Here the blog ideas about social responsibility of colleges and universities try to boil down that is what he said at the University of Responsibility is the core of university academic responsibility, the other is affecting the university existence and performance of the core responsibility outside the academic responsibility. In the figure one, we show the principles. To strengthen college students' psychological health education work that is under the new situation to fully implement the party and the national education policy, 
implements the education for all-around development the important measure is to cultivate all-round development of innovative talents is an urgent need to that is to develop students as the important form, meet the requirements of the students to grow up, is to strengthen and improve ideological and political education work in the content, ways and methods on the extension and expansion.

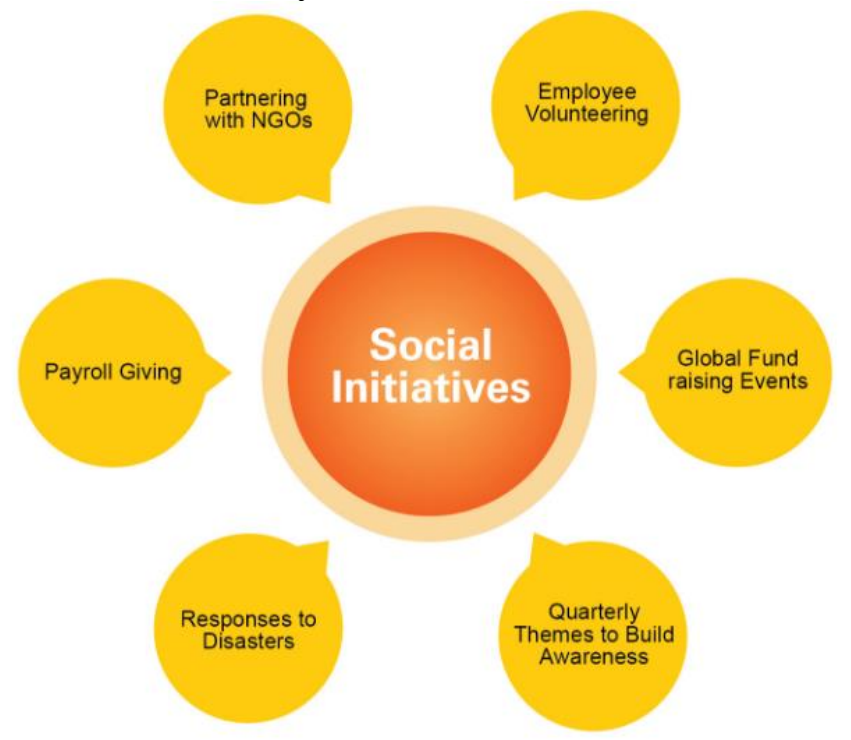

Fig. 1 the General Components of the Professional and Social Responsibility Perspective

\section{The Proposed Methodology and Perspective}

\subsection{Mental Health Education Principles.}

About the definition of mental health, most people tend to a positive and continuous development of psychological situation as the individual under this kind of condition has a good adaptability can give full play to the potential of body and mind, and is much more than the absence of mental illness. It contains two meanings: one is the psychological state of normal and the second is to actively adjust their own state of mind, can adapt to the environment and constructively effective development and the improvement of personal life.

At present, people's understanding of mental health mainly has two kinds: one is the understanding of the clinical psychiatry. They think that since the antonym of "health is not healthy, so the most straightforward definition is no symptoms of the psychological state of mental health, namely the psychological function is the normal, no psychological symptoms. It is easy to clinical operation, but simplification, the problem of mental health should be narrow, negative and another major is the understanding of the humanistic psychology, psychological state is stable, has a setback, meet the challenge, adapt to the environment of good personality quality is the person's potential and creativity into full play, to realize the value of life better.

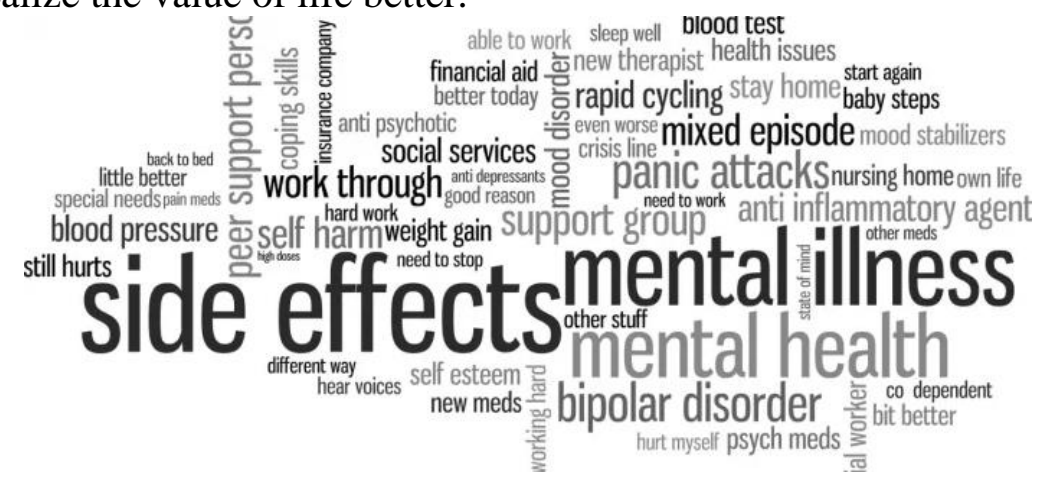

Fig. 2 the Keywords of the Mental Health Education

Therefore, improving the students' psychological quality and strengthen the school mental health education is imperative. However, due to the school mental health education is a highly scientific, the professional and technical work, at present in our country is still in its initial stage. 


\subsection{College Mental Health Education Features.}

Colleges and universities should insist on school mental health education personnel training, obey the demands of the school student management follow the basic principles of the campus stability. College psychological health education work is a student thought political education work shall form an integral part of, as a result, the college psychological health education work with four combination of ideological and political education work to do as the follows.

- From the point of view of organizational structure, mental health education system in colleges and universities should is the job of the multiple three-dimensional model. In order to ensure the standardized and orderly the school mental health education, a system of the reasonable structure, perfect multiple three-dimensional working modes are very important. Leader in charge of the school, students, teaching and management departments, departments (the department), the teacher in charge (counselor), community and the student cadre should be incorporated into the mental health education working system.

- Look from the job functions, college psychological health education work should be multiple three-dimensional divisions of functions. A single way of working can't produce the effect of comprehensive, college psychological health education initiatives should also implement multiple three-dimensional, in-class and after-class, combining education and basic guidance, consulting and self-help, multi-channel, promote the development of students' mental health. In particular, it can be summarized as "a position, four kinds of combination.

\subsection{Social Responsibility and the Career Perspective with Mental Health Education.}

In recent years of practice, career planning education in the curriculum construction, theoretical research, professional team building and so on has made gratifying achievements, but there also exist is not consistent with the knowledge of college students, job requirements, not with the whole school work that cannot be combined with a working group of the students, etc. Career design, there are two different perspective, a personal career design, second, the organization for employee career design. These are the two relatively independent and interrelated aspects. Organization for employee career design can help employees in a certain stage of life to achieve his personal career design. At the same time organization for employee career design is the organizational development needs and personal career development needs together. So, the organization for employee career design is refers to the personal development and organizational development, combining the decision of the personal career personal factors, organizational factors and the social factors were analyzed, and develop employees within the organization career development strategic ideas and plans.

Modern philosophy mainly includes employee career design as follows. (1) Employee, supervisor, the human resources department, school jointly responsible for the employee's career design. (2) Employee career design soul as is to make the individual career needs and organization coordinated development needs can make the organization and its staff common development. This is the guiding ideology, staff career design starting point and destination. (3) We should attach great importance to the staff's personal career development needs, depending on the employee's personal responsibility for one's career development for organizations and their managers. (4) Organizations and individuals have their own requirements and selection, employee career design is combined with organization's development goals and personal career development.

In our country, with the development of the socialist market economy and the construction of the socialist democracy under the rule of the law, with the progress of science and technology and the national socialization process of speeding up, the citizen moral education in the whole society has increasingly become an important theoretical and practical problems, and to strengthen and improve the responsibility education of contemporary college students has become the inevitable demands of the modern society. China's current economic situation is given priority to with public universities, higher education system this characteristic determines the entrusted resources in basic colleges and universities public product characteristics; But due to the limited funding, as well as the college education and scientific research products have some private product attributes, can be competitive, which in turn makes the resources of colleges and universities and the product is different from the 
compulsory education, should belong to the accurate public goods, in a fully between government supply and completely private supply.

Therefore, colleges and the universities public fiduciary duty is a combination of the economic responsibility and social responsibility, and both are largely promote each other, complement each other. At present, the public colleges and universities in the process of service society show "part of the lack of social responsibility idea and weakening, social responsibility to perform the structural imbalance and inefficiency", based on the real demand perspective, the social responsibility of the supervision and evaluation in colleges and universities is imminent. The spirit of the school culture is the soul of a school culture, it is a school years of cultural precipitation, school spirit, school spirit, and managerial guiding ideology, morality, values, etc., spiritual culture on changing the students' behaviors, affecting the formation of general students' moral values. Build positive campus culture atmosphere in colleges and universities is to play to the role of the campus culture the leavening, in imperceptible in improving college students' personal quality and sense of responsibility.

\section{Summary}

In this paper, we conduct contemporary pattern analysis of mental health education in colleges under the professional and social responsibility perspective. Developmental education idea into the university mental health education is the education for all-around development request inevitably. The current mental health education practice of many universities in China still exist serious tendency to counseling, treatment, development of consciousness weak, less developmental problem of basic experiments and research that do not accord with basic principles of education. We should develop a plan of college students' psychological health education, to determine the corresponding education contents, education methods. To establish and improve the mental health education and consultation of specialized agencies, equipped with a sufficient number of mental health education teachers, actively carry out college students' mental health education and psychological counseling to guide the healthy growth of college students.

\section{References}

[1] Benjet, Corina, et al. "Youth who neither study nor work: mental health, education and employment." salud pública de méxico 54.4 (2012): 410-417.

[2] Fazel, Mina, et al. "Mental health of displaced and refugee children resettled in high-income countries: risk and protective factors." The Lancet 379.9812 (2012): 266-282.

[3] Schwind, Jasna K., et al. "Opening the black-box of person-centred care: An arts-informed narrative inquiry into mental health education and practice." Nurse education today 34.8 (2014): 1167-1171.

[4] Baker-Henningham, Helen. "The role of early childhood education programmes in the promotion of child and adolescent mental health in low-and middle-income countries." International journal of epidemiology (2013): dyt226.

[5] Edward, Karen-leigh, et al. "Motivations of nursing students regarding their educational preparation for mental health nursing in Australia and the United Kingdom: a survey evaluation." BMC nursing 14.1 (2015): 1. 